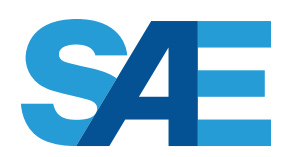

INTERNATIONAL

\title{
20 Years of UNSW Australia's Sunswift Solar Car Team: A New Moment in the Sun, but Where to Next?
}

2015-01-0073

SAEA-15AP-0073

Published 03/10/2015

\section{Hayden Charles Smith and Sam Paterson}

UNSW Australia

\section{Clara Mazzone}

CBS Power Solutions (Fiji) Ltd

\section{Sammy Diasinos}

Macquarie University

\section{Graham Doig}

California Polytechnic State University

CITATION: Smith, H., Paterson, S., Mazzone, C., Diasinos, S. et al., "20 Years of UNSW Australia's Sunswift Solar Car Team: A New Moment in the Sun, but Where to Next?," SAE Technical Paper 2015-01-0073, 2015, doi:10.4271/2015-01-0073.

\begin{abstract}
The Sunswift Solar Car project has been running at UNSW Australia in Sydney for 20 years as of 2015. It is an entirely student-run endeavour which revolves around the design and development of a solar/electric vehicle nominally designed to compete in the World Solar Challenge rally from Darwin to Adelaide every 2 years. The student cohort is drawn from a range of schools, disciplines and backgrounds, and the team has been increasingly successful and high-profile particularly in its second decade. The excellent level of hands-on training that the project provides to students is not rewarded with academic credit yet many of the alumni credit the project with launching their careers and ambitions. The team's world recordbreaking latest vehicle, eVe, is the fifth constructed and presents a radical departure from previous cars in that it carries a passenger in a conventional layout and is based around a road-going sports car. The team is currently working to meet road registration standards, making it the most complex vehicle yet. However, the issues of high costs, safety concerns, ensuring representative student participation, and student workload management present ongoing challenges which must be met if the project is to continue its run of success.
\end{abstract}

\section{Introduction}

Project-based learning in engineering has been widely shown to be an exceptionally effective method for empowering students to learn fundamental principles of science and develop a practical understanding of how to apply them in engineering to solve real design problems [1]. Students value a realistic environment in which to see designs from a systems perspective and appreciate technical challenges in the context of wider global economic, societal and environmental requirements [1]. It is seen as an effective tool to develop life-long learning, practice and refine technical expertise, and to reinforce engineering management principles [2].

UNSW Australia's Sunswift Solar Car Racing Team is currently Australia's most high-profile solar car team, and is the Faculty of Engineering's flagship student project. 2015 marks Sunswift's 20th year. Following a string of in-class wins in the World Solar Challenge (WSC) in the last 6 years, the "brand" has built an international profile with two major land speed records. A recent peak in achievements - with a car that more closely resembles a "normal" vehicle than any of its predecessors - coincides with significant renewed public/industry interest in electric vehicles. This has helped give solar-powered vehicle racing a "second moment in the sun" following many years of public disinterest in more homogenous, impractical designs.

Solar car projects in the educational setting are relatively closely related to the more common and familiar F-SAE design-build-race projects. However, vehicles constructed for the WSC can be an order of magnitude more expensive to build due to the cost of solar panels, batteries, high-efficiency electric motors and controllers, and the near pre-requisite use of composites for much of the car. For overseas teams there is the expense of travelling to Australia with a car and team to race there. The race itself is held across $3000 \mathrm{~km}$ on public roads and is therefore considerably more risky than a controlled F-SAE or EcoMarathon event, and the vehicles require amongst the most broad range of skills, talents, backgrounds and disciplines of any student engineering project. The Sunswift project has been an excellent training ground for hundreds of UNSW undergraduates in everything from composites, photovoltaics (PV), electric motors and 
control systems, aerodynamics, marketing and PR, health and safety, manufacturing techniques, to project management, systems engineering, and industrial design at large and small scales.

The team's most recent vehicle "eVe", a 2-seater solar supercar, has been changing the public perception of what a solar car can be. In the team's current pursuit of having eVe certified as road-legal for unrestricted use, Sunswift arguably represents Australia's most ambitious and comprehensive undergraduate automotive project. The scope and scale of the project presents many challenges enhanced from previous years, such as increased opportunity cost for students working long hours for no academic credit, the increase in required budget, and how to manage the engineering and safety concerns at all levels. However, these challenges serve to further enhance the industry-relevance of the training, with new considerations of legitimate safety structures, driver/vehicle interfaces, powermanagement strategies for regular city vs. highway driving, and an overall systems engineering approach.

The paper is divided into three sections reflecting the aims: 1) a historical overview of the team's evolution including descriptions of the vehicles and successes and failures of the distinct eras to give context to the project and its present state - this information has not been previously compiled in the public domain; 2) a description of the engineering and team of the present vehicle as well as the current challenges faced - we expect this information to be of value to other solar car teams as well as of interest in the automotive field in general; and 3) a discussion of the project's educational and broader impact, with an eye to the future direction of the hands-on learning and outreach that the project can offer.

Note that the authors are comprised of the current and three former team project managers, as well as the most recent academic advisor; as such, much of the information presented in this paper is drawn from direct experience. A small (8 person) non-discriminate selection of alumni was interviewed to provide the quotes used to inform some points of discussion where more subjective material is introduced.

\section{An Overview of Sunswift, 1995-2012}

Sunswift, otherwise known as UNSW Australia Solar Racing Team (SRT), has no written "mission statement" per se, but it is accepted by students and academics that the goals of the project are threefold: to provide challenging, hands-on, real world student training in design and manufacture of a solar electric vehicle to compete in the World Solar Challenge; to be a platform for broad promotion of UNSW Australia's engineering programs and schools; and to demonstrate renewable energy and sustainable transport technologies and possibilities to the public and, particularly, the upcoming generation of primary and high school students (which is implicitly linked to the second goal).

Sunswift was initiated by Byron Kennedy, a final-year electrical engineering student at UNSW in 1995. The intention was to compete in the WSC, by then a well-established rally for vehicles with relatively small batteries charged entirely from solar panels mounted to the vehicle. Entities such as GM and Honda had competed in earlier versions of this race, been successful, and largely ended their involvement. This left a competitive field of mostly university-built vehicles to take part in the event every 2 to 3 years.

The original Sunswift vehicle was not built from scratch by the team, but purchased from the Aurora Vehicle Association in 1996. The team worked on modifying or designing new components, including a motor controller, revised chassis and roll cage, and batteries. Despite being an older vehicle, the car placed $9^{\text {th }}$ in the World Solar Challenge out of a field of 46 , and this performance as well as the perceived prestige of running a solar car racing team ensured that the project would continue into a new phase of designing vehicles at UNSW. Since then the project has produced four cars, and provided training and unique practical experience for hundreds of students well over 100 of whom have known the thrill of racing in the WSC.

Figure 1 shows the 1995 team with Sunswift I; a summary of the vehicle is given in table 1 . In the subsequent sections, a short overview of the each vehicle is presented along with notes on successes and failures during the different eras of teams which have raced each vehicle.

\section{Sunswift II}

After the 1996 WSC, the UNSW SRT commenced preparations for the design and construction of an all-new solar car, Sunswift II (figure 2). From the very beginning, aerodynamic performance was prioritised with a series of wind tunnel and CFD (computational fluid dynamics) tests resulting in a vehicle that minimised the wetted area while ensuring that the maximum allowable array area of $8 \mathrm{~m}^{2}$ was achieved. The driver was centrally located, requiring a canopy that was blended into the aerofoil-shaped body, resulting in a complex curved array surface. The single rear driving wheel and the two steered front wheels were independently suspended from a chromemoly space frame which utilised a structural seat.

The chassis and body shape of Sunswift II became the catalyst for numerous significant technical innovations over the course of the next seven years. This included a bespoke structural aluminium in-wheel motor casing, composite wheels, and the implementation of a unique CAN (Controller Area Network) telemetry system.

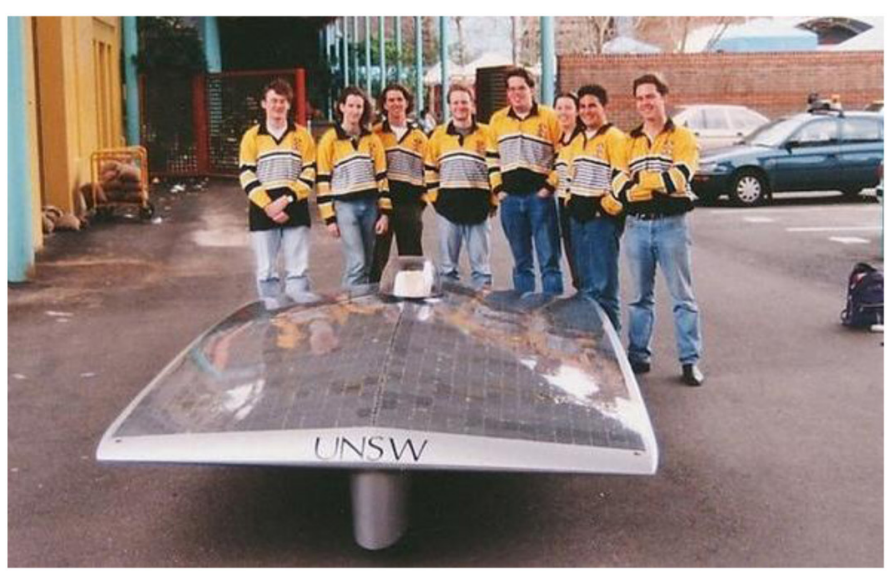

Figure 1. Sunswift I and team, circa. 1996. 
Table 1. Sunswift I details.

\begin{tabular}{|c|l|l|}
\hline Vehicle & \multicolumn{1}{|c|}{ Stats } & \multicolumn{1}{|c|}{ Achievements } \\
\hline & L $\times$ W: $4.46 \times 2 \mathrm{~m}$ & \\
& Array: & \\
Sunswift I & $\begin{array}{l}7.88 \mathrm{~m}^{2} \text { at av. } 18.5 \% \\
\text { efficiency }\end{array}$ & $9^{\text {th }}$ overall, 1996 \\
(formerly & Battery: $3 \mathrm{kWh}$ & Corld Solar \\
Aurora Q1) & Top speed achieved: & \\
& $63 \mathrm{~km} / \mathrm{h}$ & \\
& Weight: $255 \mathrm{~kg}$ & \\
\hline
\end{tabular}

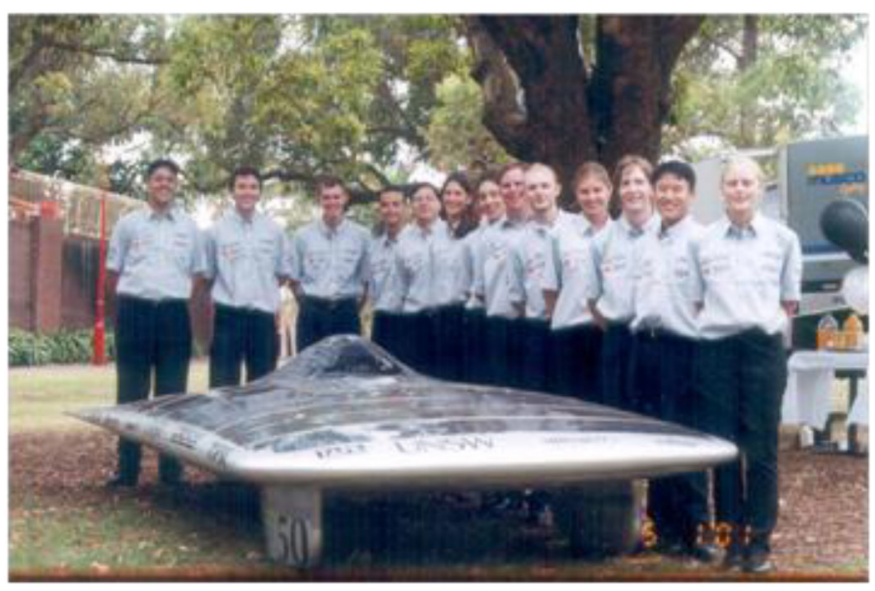

Figure 2. Sunswift II, team circa. 2001 (photo credit: Sammy Diasinos)

But the two most elaborate and ambitious projects were undertaken in preparation for the 2001 WSC. In the prior year, more than twenty volunteer students undertook the manufacture of 8000 buried contact solar cells using the photovoltaics facilities at UNSW: the Topcell Project. In the process, this group of students established a relationship with a silicon wafer supplier (Topsil), broke the efficiency record for buried contact solar cells, and manufactured adequately high yield rates to not only achieve the necessary cells for a competitive 2001 WSC entry, but also to supply several small local satellite projects with solar cells. Concurrently, progress was being made on a solar cell encapsulation technique that would allow the solar modules to be moulded into the complex shapes that the aerodynamic shape of the vehicle dictated. To achieve this, it was necessary to determine how to mould the front and back skins of the laminate, construct a mould that could withstand the pressure required for the lamination technique and to assemble a telemetry system that would monitor the temperature to ensure the most appropriate curing process. The end result was a solar array which did not stress the encapsulated cells, and eventually generated $1350 \mathrm{~W}$ while also providing the best aerodynamic finish ever achieved by the team. The car could sustain $100 \mathrm{~km} / \mathrm{h}$ with $1800 \mathrm{~W}$.

Table 2. Sunswift II details.

\begin{tabular}{|c|l|l|}
\hline Vehicle & \multicolumn{1}{|c|}{ Stats } & \multicolumn{1}{c|}{ Achievements } \\
\hline \multirow{3}{*}{ Sunswift II } & L x W: $4.4 \times 2 \mathrm{~m}$ & $3^{\text {rd }} 1999$ SunRace \\
& $\begin{array}{l}\text { Array: } 8 \mathrm{~m}^{2} \text { at approx. } \\
19.5 \% \text { efficiency. }\end{array}$ & $18^{\text {th }}$ overall, 1999 WSC \\
& $\begin{array}{l}\text { Battery: } 3 \mathrm{kWh} \\
\text { Top speed achieved: } \\
\text { Approx. } 120 \mathrm{~km} / \mathrm{h}\end{array}$ & $2^{\text {th }}$ overall, $2001 \mathrm{WSC}$ \\
& $\begin{array}{l}\text { neight: } 180 \mathrm{~kg} \\
\end{array}$ & $2^{\text {nd }}, 2002$ SunRace \\
\hline
\end{tabular}

While the 2001 campaign was hugely successful from an innovation perspective, the expense required to achieve these developments far exceeded the external support that could be raised, resulting in the faculty funding almost half of the cost of the project. This level of support from UNSW was generous considering the trials that the team endured during the previous campaigns: the 1999 WSC included a sponsor's vehicle being involved in a car accident that prevented it from being used during the event, and a team member being injured after tripping while attempting to put out a small battery fire that had started in a trailer. The latter resulted in the team member having to be air lifted from Cooper Pedy to Adelaide to receive medical treatment. Evaluation of these events led to much more thorough preparation procedures: at the following Sunrace 2000, the team's excellent on road performance was abruptly and prematurely ended when Sunswift II was forced off the road to take evasive action due to a lack of awareness from another road user. In 2003, en route to the WSC, the tow vehicle and trailer carrying the car rolled and Sunswift II was damaged beyond immediate repair - ending a period of the team marked by intense innovation and exceptional engineering development, but also mixed results, and numerous incidents serious enough to make the university nervous.

\section{Sunswift III}

From the outset, the aim of UNSW Sunswift III was to design the world's most efficient solar car while also pushing the boundaries at the time, of practicality (figure 3). The team identified all possible improvements to Sunswift II with a view to modifying the existing systems and methods for making the car as efficient as possible. The car could also carry a passenger (facing backwards) behind the driver - in retrospect the first step towards the present-day passenger-carrying "practical" car. The end result was a car with $2 \mathrm{~kW}$ of array and a $2.5 \mathrm{~kW}$ lithium ion battery enabling a top speed of close to $130 \mathrm{~km} / \mathrm{hr}$. The efficiency and performance of UNSW Sunswift III in the 2005 World Solar Challenge was excellent. The push-pull tank steering, however, was less than effective and proved difficult for drivers to control, leading to the vehicle hitting a sign post in testing just before the race: thus the car was not an official participant in this 2005 WSC. In preparation for a Transcontinental World Record Attempt (west to east across Australia), the brakes and steering systems were redesigned to reduce weight, increase the driver comfort and maneuverability, and improvements were made to the electrical system. In January 2007, Jaycar Sunswift III broke this record, completing the $4000 \mathrm{~km}$ drive from Perth to Sydney in 5.5 days.

In September 2007, the team successfully completed the WSC in 9th place overall and $4^{\text {th }}$ in "Adventure" class for older, larger vehicles, and was also awarded the CSIRO technical innovation award out of an field of 41 international entrants. The same year, the Sunswift team was awarded the 2007 Engineers Australia Engineering Excellence Award for Education and Training. The philosophy for 2007 was to avoid, entirely, any of the kinds of accidents or injuries which had marred the previous several races, and to be less aggressive in pursuit of results - for all concerned, the pleasing outcome of this strategy was a high-water-mark of achievement in results anyway. 


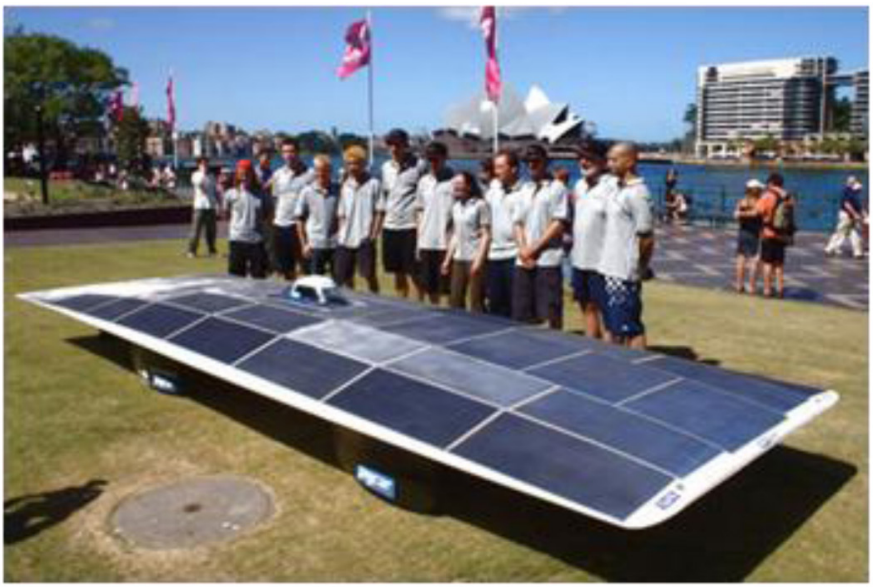

Figure 3. Sunswift III and 2006/07 team.

\section{Sunswift IVy}

There was a major turnover of team personnel when Sunswift III retired - the team to design and construct the $4^{\text {th }}$ vehicle started with a project manager and not much more. Some alumni eventually rejoined the team; in such situations a lot of knowledge is preserved if mentoring relationships can be established with previous team members. The continued halo presence of alumni has always been an important ingredient in Sunswift, although in the IVy era formalization of this as well as detailed leadership succession planning was not yet implemented.

Table 3. Sunswift III details.

\begin{tabular}{|c|c|c|}
\hline Vehicle & Stats & Achievements \\
\hline Sunswift III & $\begin{array}{l}\mathrm{L} \times \mathrm{W}: 6.0 \times 2 \mathrm{~m} \\
\text { Array: } 11.5 \mathrm{~m}^{2} \text { at av. } 20 \% \\
\text { efficiency } \\
\text { Battery: } 2.5 \mathrm{kWh} \\
\text { Top speed achieved: } \\
\text { Approx. } 120 \mathrm{~km} / \mathrm{h} \\
\text { Weight: } 220 \mathrm{~kg}\end{array}$ & $\begin{array}{l}9^{\text {th }} \text { overall, } 2005 \\
\text { WSC * } \\
4^{\text {th }} \text {, Adventure class } \\
{\left[9^{\text {th }} \text { overall], } 2007\right.} \\
\text { WSC, \& CSIRO } \\
\text { Technical } \\
\text { Innovation Award } \\
\text { Australian } \\
\text { Transcontinental } \\
\text { solar record: } 5.5 \\
\text { days } \\
\text { * (unofficial entry) }\end{array}$ \\
\hline
\end{tabular}

IVy (figure 4) was specifically built to compete in the 2009 WSC - by then the rules had dictated that solar array area be limited to $6 \mathrm{~m}^{2}$ and the driver had to sit in a relatively upright position, leading to the emergence of "bumpods" across the competitive field, where the main driver space would extend below the wing-shaped main body towards the ground (increasing vehicle drag). The team collectively felt that it would be possible to challenge for a highest-ever finish with this relatively clean slate of rules, however as had been the case in the preceding few races, the best-funded teams had access to Gallium-arsenide arrays which UNSW would not be able to obtain due to the unjustifiable expense.
IVy could also be interpreted as marking the point at which the team's pursuit of major technical innovation subsided in favour of subtle but valuable developments such as complex strategy modeling and initiatives such as "sunswift live" to allow people worldwide to follow the car in real time and get updates on speed, energy usage, etc. The vehicle's shape was determined entirely through the use of CFD, with a real-world drag coefficient of 0.09 - the design philosophy was based around a dynamic-looking, minimal-frontalarea shape which would perform well in crosswinds and everchanging conditions in the outback rather than the most pure efficiency one might develop in the "perfect" conditions of a wind tunnel alone [3]. The car proved to be the best-handling vehicle produced to date, and had negligible problems in windy conditions even when support vehicles were battling gusts in the outback. It is also the first vehicle where minor, purely-aesthetic touches (the "batwing" trailing edge, the rear of the driver canopy hanging off the rear of the chassis) were introduced to distinguish the design from what was by then very much the "default" design pioneered and refined by TU Delft's multi-race-winning Nuna series - exceptionally efficient and accomplished designs which are nevertheless not readily distinguishable from each other by a layperson.

The build schedule was exceptionally tight, resulting in the car being late to its own launch, and travelling to the WSC as a largely untested prospect. Debates were held on whether the car should be allowed to compete on safety grounds, given its lack of mileage before the event. The car and team exceeded even their own expectations by coming through the field strongly from a poor qualifying performance, eventually finishing $4^{\text {th }}$ overall and $1^{\text {st }}$ in the "Challenge Class, Silicon" for vehicles with conventional arrays, marking a new high-point for WSC results. After some mechanical modifications, a new array, a rebuilt chassis, and other improvements, the car achieved $6^{\text {th }}$ in the 2011 WSC. The relative drop in results can be attributed to being "locked in" to a design while most other top teams constructed new and improved vehicles. This not only can compound design issues which would be reworked if a blank page were available, but it has also been noted by team members of the era that it is markedly more difficult to motivate a team of new students who do not feel "ownership" or a deep "emotional attachment" to a vehicle they did not design and build themselves.

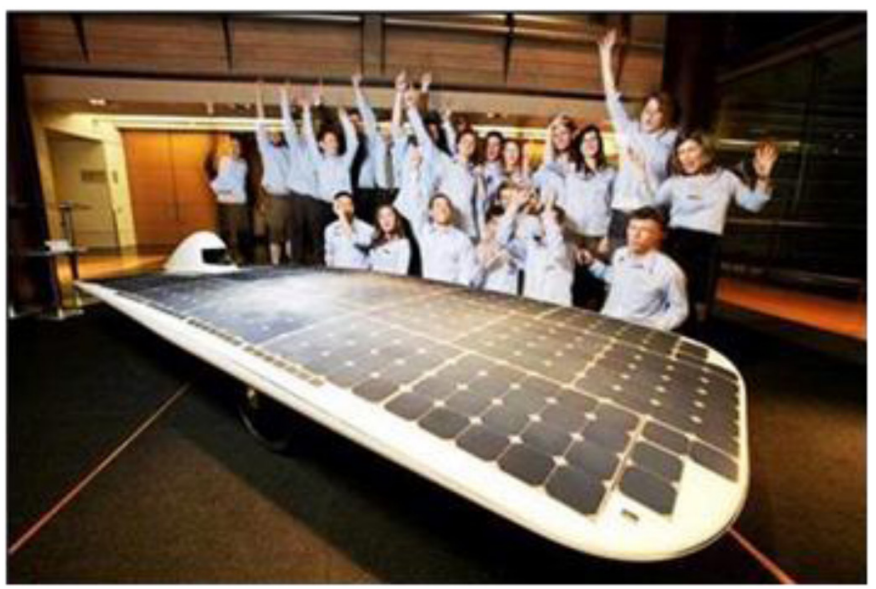

Figure 4. Sunswift IVy and team, 2009 


\begin{tabular}{|c|c|c|}
\hline Vehicle & Stats & Achievements \\
\hline Sunswift IVy & $\begin{array}{l}\text { L x W: } 4.6 \times 1.8 \mathrm{~m} \\
\text { Array: } 6 \mathrm{~m}^{2} \text { at av. } 21 \% \\
\text { efficiency } \\
\text { Battery: } 4.85 \mathrm{kWh} \\
\text { Top speed achieved: } \\
110 \mathrm{~km} / \mathrm{h}(88.7 \text { on solar } \\
\text { alone) } \\
\text { Weight: } 165 \mathrm{~kg}\end{array}$ & $\begin{array}{l}1^{\text {st }} \text { (Silicon Class), } \\
2009 \text { WSC } \\
\text { (renamed Global } \\
\text { Green Challenge) } \\
{\left[4^{\text {th }} \text { overall }\right]} \\
1^{\text {st }} \text { (Production } \\
\text { Class), } 2011 \mathrm{WSC} \\
{\left[6^{\text {th }} \text { overall }\right]} \\
\text { Guinness World } \\
\text { Record: Fastest } \\
\text { solar-powered } \\
\text { vehicle }(88.7 \mathrm{~km} / \mathrm{h})\end{array}$ \\
\hline
\end{tabular}

"A good result in '09 introduced some complacency, as in "we know this car will go well", and also it was hard to get the newbies to put in the hours in the workshop, the sense of urgency wasn't there", commented a former project leader.

Nevertheless, to give the team an exciting interim goal to work for in 2010, a long-gestating idea to break the land speed record for a solar-powered vehicle was put into action. Securing a suitable venue was the primary challenge, with record rules dictating two runs in opposite directions over the mile/km on a near-perfectly flat track. The extensive runways of HMAS Albatross in Nowra, NSW, were suitable for a Guinness-officiated record, but not an FIA-compliant attempt, thus the record strategy centered around generating media for the Guinness mark, with the Guinness brand having high public awareness. With the batteries removed so the array could provide direct drive, and despite the runs being conducted mid-morning on a partly cloudy day, worldwide print, TV and internet coverage resulted when a new top speed of $88.7 \mathrm{~km} / \mathrm{h}$ was achieved. IVy is now a popular display in the lobby of UNSW's Tyree Energy Technologies Building on the Kensington campus.
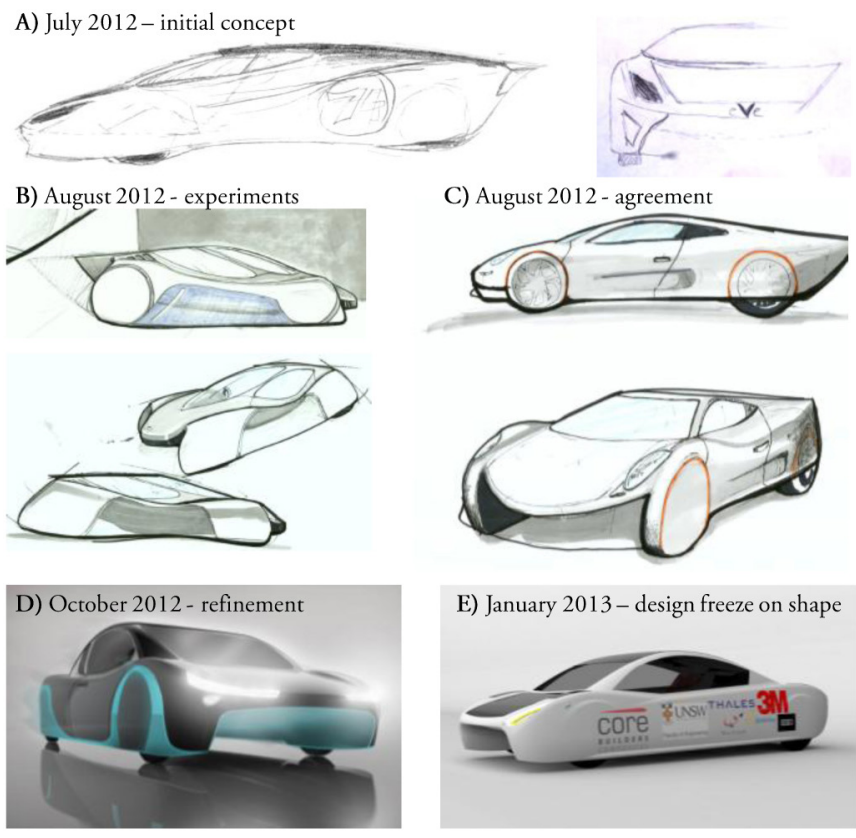

E) January 2013 - design freeze on shape

Figure 5. Sunswift eVe shape: concept to design freeze.
While Sunswift has been an often high-profile, sometimes trailblazing project, it is clear that there have been some significant downs along with the ups, and it is also pertinent that each iteration of the team has faced significant pressure from the Faculty of Engineering due to cost and safety concerns - every team leader can recount a point at which the project was close to cancellation for either of these reasons or combinations of both. Other factors only constant in their variability have been issues around retaining key people, recruitment of competent new members, internal budget squeezes, general team cohesion, difficulty in attracting high-level sponsorship, and leadership experience and ability. There is now a more active and documented focus on addressing all of these aspects to degrees, as will be touched on in later sections.

\section{2 to the Present: Sunswift eVe}

In the newly-forming team of 2012 there gradually built consensus that IVy was about as far as a quarter-of-a-million (in-kind as well as cash; much more of the former than latter) budget would stretch. It was well-designed and successful, and yet simply could not catch the top teams from Tokai, TU Delft, and the University of Michigan, amongst others. The model of the top European solar racing teams involves a dedicated team of masters students working full-time on the car as their final year, and the Dutch in particular have shown this to be a very formidable approach (sweeping both major class wins at the 2013 WSC, for example). Michigan have a multi-million dollar budget and close ties to the US auto industry. Tokai has exceptionally willing industry-leading partners for batteries and solar cells. The Aussie underdog model of do-ityourself low-budget ingenuity can only go so far against such competition; top-tier solar car racing is increasingly a semiprofessional enterprise even at the university level.

The incoming team coalesced around the potential to build a true solar-electric hybrid supercar even before the new "Cruiser class" rules were announced - ones which called for 4-wheel passenger vehicles, normal seating positions and visibility, and additional judging criteria for practicality. Several vocal Sunswift alumni were against this category, arguing that it was not about pure solar racing, and diluted the speed and appeal. The counter-argument was pragmatism about the appeal of finishing a race mid-table with a conventional and evolutionary car, garnering negligible media coverage or public interest in the attempt. The chance for the team to be at the forefront of a major new initiative - for, arguably, the first time since Sunswift II - prevailed.

Therefore in mid-2012, Sunswift embarked on a risky strategy to win the newly-established category - the risk coming from the new set of engineering challenges (no previous Sunswift vehicle ever had a door, as an example); the strong likelihood of increased expense on a project that had run over budget considerably on the previous build cycle; and operating in a highly risk-averse climate of the Faculty which saw students prevented from operating mills, lathes and other machinery even if certified competent. This was not a reaction to any incident or accident, but a blanket preventative policy. Later in the project this would lead directly to an estimated $20 \%$ of the total cash budget just for machining parts, and a legacy of students untrained in essential techniques and tools for actual manufacture: a situation incompatible with designing and building racing cars, and something which must be readily addressed before the 2016/17 build. 
The 2012/13 philosophy that emerged for eVe was to build a car that had such instant public appeal from evocative, surprising aesthetics and performance that it would be a relative media superstar at the WSC and beyond. Figure 5 outlines the initial design stages from concepts to the finalized shape at the end of the 4-month aero development program. The nature of the WSC race (solar yield at its best from the North) virtually dictated the long sloping rear upper surface for PV area and power potential. This fit best with design inspiration taken from mid-engine supercars such as the McLaren MP-412C, Pagani Huryana, and various Lamborghinis, rather than the more classical curvaceous coupe styles more synonymous with Aston Martins and Maseratis, or the rawer, squatted American-muscle marques. Early input from industrial designers was essential in educating the engineers on the "language" of car design. However the designers also needed education on the nature of solar cars - the requirements for array performance, huge aesthetic compromises made for aerodynamic gains, etc. The relationship between the two groups was not well integrated and aerodynamics became dominant (figure 5). As a result the car looks striking and dynamic from some angles, and an unusual mish-mash of styles from others - there has certainly never been a solar car like it.

As with IVy, the aero development phase was entirely CFD-driven, due to the lack of a suitable wind tunnel to achieve realistic Reynolds numbers, and a lack of a moving or even elevated ground. The aero team was mentored by IVy's designers, ensuring a very rapid establishment of reliable methodology. Around 50 design iterations were then tested over the course of approximately 3 months, initially with major aesthetic changes and a problem-solving approach, then later with minor modifications to chase reductions in downforce (to reduce rolling resistance) and to further improve the looks. The "chopped" blunt rear of the car where the lights and license plate sit is one such concession to visuals that was later quantified as costing $5 \%$ in drag, but contributes greatly to the appearance of the car as a conventional vehicle. The main design breakthrough in the early stages was the introduction of a dual-level tunnel running underneath - the reduction in frontal area and the efficient guiding of air to the rear of the vehicle to achieve only a slight downwash in the wake ensured attached flow over the entire body, bar the exposed portion of the wheels and a small vortex from the c-pillar. In this phase, the area drag coefficient, $\mathrm{C}_{\mathrm{D}} \mathrm{A}$, dropped from an initial 0.29 to 0.16 in the space of a few weeks. The final $\mathrm{C}_{\mathrm{D}} \mathrm{A}$ of the vehicle was approximately $10 \%$ lower after 2 months of further tweaks - at this point a design freeze was implemented. The array team had only recently been formed and were locked in to certain space and shape constraints that compromised maximum potential array output by at least $5 \%$.
Solar array:

Sunpower $\mathrm{C} 60$ cells Two drivetek MPPTs - curved array tricky.

Max output approx. $0.85 \mathrm{~kW}$

\section{Battery:}

1326 Panasonic NCR18650B Li-lon

cells

$16 \mathrm{kWh}$ of power

$63 \mathrm{~kg}$ weight
Suspension:

Independent front (double-wishbone) and rear (trailing arm) systems.

Powertrain:

Wavesculptor 22 motor controller. 2x CSIRO / Marand in wheel motors permanentmagnet
Steering:

Collapsable. Allows for $8 m$ turning radius (max) 
Renders of the vehicle instantly became a vital tool on social media and for attracting the interest of potential sponsors. Since manufacture, positive response to the car's appearance has been the major drawcard in the marketing and brand recognition of the team.

\section{About the Vehicle}

"eVe" as built in 2013 is a mechanically-simplistic car by any modern standards, but represented a giant leap for the students at UNSW Australia. Figure 6 presents a cut-away diagram showing the general construction and layout of the vehicle with the main design components described. The vehicle is approximately $4.5 \mathrm{~m}$ long and $1.8 \mathrm{~m}$ wide as dictated by WSC rules, with the majority of the $4 \mathrm{~m}^{2}$ of external solar on the roof and bonnet (hood) - additional panels were squeezed onto the "shoulders" above the wheel arches. The wheels themselves were inset from the vehicle extremities to allow them to remain fully enclosed at maximum turning angle, for aerodynamic reasons. The wheel wells were initially not sealed for the WSC - they now are, to prevent debris and unwanted air entering the interior.

The solar array consists of Sunpower C60 cells which achieved close to $22 \%$ efficiency post-encapsulation. The curves of the body meant that the maximum array output was only $850 \mathrm{~W}$, considerably down on the $\sim 1.2 \mathrm{~kW}$ of its predecessor. Two drivetek maximum power point trackers (MPPTs) were utilized. The MPPTs consist of a boost converter which steps up the voltage of the strings from their typical $50-70 \mathrm{~V}$ to that of the high voltage bus at a nominal $140 \mathrm{~V}$. In addition to this, the MPPT runs an algorithm to optimize the operation of the solar cells by keeping the strings operating at their maximum power points and drawing the right amount of current from each of the strings for the present illumination conditions. The battery was 16 $\mathrm{kWh}$ of lithium ion cells from Panasonic - the battery pack itself was situated close to the front of the car, with the Wavesculptor 22 motor controller towards the rear. The choice of cells was optimized for the maximum energy to weight $-253.89 \mathrm{Wh} / \mathrm{Kg}$ - with a voltage range of $113.1 \mathrm{~V}$ to $163.8 \mathrm{~V}$, yielding a capacity of $113 \mathrm{Ah}$. All telemetry data is collected by a Xbee wireless RF module.

Carbon fibre composites were used to construct the vast majority of the interior and exterior. From a partnership with Core Builders Composites in New Zealand, a sub-team of a dozen students were able to travel there and over an intensive two weeks were assisted and mentored in all aspects of manufacture. Universally, the students reported overwhelmingly positive feelings about the experience, which exposed them to a level of design professionalism they had not previously encountered, as well as a work ethic which could not have been achieved in their normal workshop and without strict deadlines. The quality of the carbon work and the final finish speak to the value of the partnership for both the product and the training. The chassis comprises a top and bottom shell with three thicker nomex honeycomb core sandwich bulkheads for lateral and torsional rigidity.

Regenerative braking is preferred in almost all circumstances, though dual redundant mechanical front brakes are installed. The wheels themselves feature composite rims and the car is rear wheel drive, with two integrated $2 \times$ in-hub axial flux, permanent magnet, synchronous DC motors mounted in the rear wheels, achieving $98 \%$ peak efficiency. The 2013 WSC was run with narrow Michelin Solar Radial tyres, which wear rapidly in cornering but offer very low rolling resistance in a straight line.
The rear suspension was designed as a trailing arm arrangement - the shape of the car had been fixed before detailed design on this component, leading to difficulties in fitting the space available. Front suspension was independent, double-wishbone. Extensive static structural finite-element analysis (FEA) using ANSYS was carried out on most of the major components of the car, including the chassis. Very little validation or destructive testing was possible, and digital structural analysis of composites is a challenging undertaking at the undergraduate level. Therefore, relatively conservative design margins were established, typically at least 2 times the anticipated failure levels but often considerably higher.

Sunswift eVe is designed to handle like a typical road-going passenger vehicle, and does so through the implementation of the Strange Engineering S3447 Dragster Box, a 12:1 ratio rack-andpinion unit. Ackermann steering conditions are closely approximated, which enables the car to turn whilst minimizing scrub of the tyres. This steering system is also designed to allow the car to perform a $16 \mathrm{~m}$ kerb-to-kerb U-turn.

Similar to the suspension, the steering and doors were designed subsequent to the design and manufacture of the body shape due to the window of opportunity to build in New Zealand, leading to compromises on door integrity (gaps at the roofline lead the panel to twist outwards at speed due to low pressure over the A-pillar) and ergonomics (a steering wheel too close to the driver, and supported by an ungainly frame structure in the cabin); all of these issues are now being addressed in the second iteration of the car. The team maintained a can-do attitude of keeping an eye on the main priority getting the vehicle running. However, as these complications arose, urgent action was taken to prevent the project derailing, resulting in the team reaching out to mentors drawn from industry (Thales) and specifically motorsport (Envirage, Caterham F1) to facilitate regular reviews. A dramatic improvement in design thinking and information presentation was achieved in a short space of time, as the mentors pulled no punches and instilled a firm sense of responsibility in the student engineers.

As the scope and ambition of eVe became apparent, an unavoidable squeeze on all phases occurred, as summarized by figure 7 showing a monthly countdown to the WSC, planned and actual - the most vital aspect being a near-complete lack of testing of the vehicle prior to the WSC. Enthusiasm amongst the student body and team supporters, however, had never been higher - a "Pozible" crowdfunding campaign to complete the car and make the race netted over $\$ 27,000$, and the car was launched to great fanfare with national media coverage and a parade through the university.

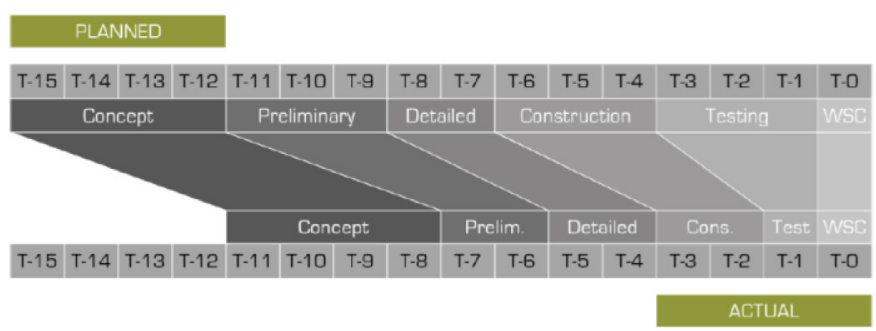

Figure 7. The 2013 build schedule; planned vs. actual (months). 


\section{Summary of Performance and Achievements}

Lack of testing before the 2013 WSC resulted in electrical issues marring qualifying, and a costly brake rubbing issue on day 1 of the race. From day 2, however, the car ran well and came from behind to take Cruiser Class line honours by a margin of almost 2 hours. eVe posted the $4^{\text {th }}$ best time of any car ( $\left.38 \mathrm{hrs}, 35 \mathrm{mins}\right)$ in the race behind the best of the single-seater, traditional "challenge" class cars that had less battery capacity but did not have to stop at defined overnight destinations like the Cruisers. Once handicap-style practicality scores were taken into account, the overall result was $3^{\text {rd }}$ in class. The car completed the fastest Darwin-to-Adelaide of any Sunswift car, the fastest average speed leg of any car in the race (sustained several hours of $110 \mathrm{~km} / \mathrm{h}$ average at $<5 \mathrm{~kW}$ power draw), the fastest top race speed of any Sunswift car $(128 \mathrm{~km} / \mathrm{h})$, and finished $2 \mathrm{nd}$ of all the volunteer, undergrad-only teams, behind Tokai and ahead of Stanford in on-road time. It was the only Cruiser Class vehicle to successfully arrive at its destination on every day of the WSC - the highest possible endorsement of "practicality". There were no injuries or serious safety incidents, continuing an exceptional run that started with the culture change of the 2007 WSC team.

In July 2014 the team, using a slightly modified version of the car with improved brakes and an extension to the rear of the vehicle to correct downwash and reduce pressure drag (between 5 and 10\% improvement to the total vehicle drag), attempted an FIA international land speed record for the fastest electric vehicle over a distance of $500 \mathrm{~km}$. The ratified official average speed was $107 \mathrm{~km} / \mathrm{h}$, with professional racing drivers Karl Reindler and Garth Waldren completing all laps of the Australian Automotive Research Centre test track in Victoria. Media coverage of this event had worldwide reach, with multiple TV interviews, web features, and online readership into the hundreds of thousands.

As an example of how "new" and relatively rare the "alternative energy" record categories currently are - and how misunderstood the vehicles and regulations are on the officiating end - eVe was required to have her solar panels covered in vinyl so no light could transmit to the photovoltaic panels.

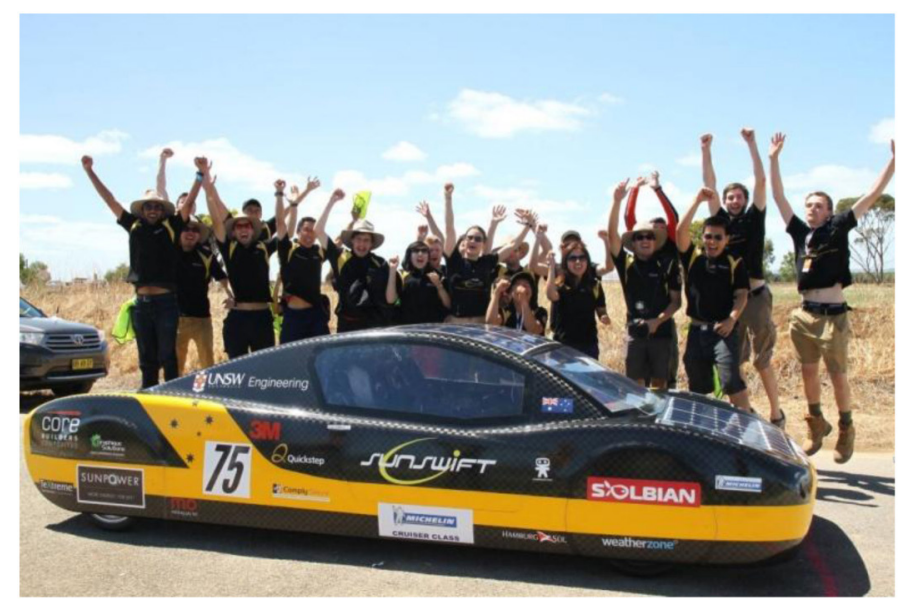

Figure 8. Sunswift eVe and the 2013 race team.
Table 5. Sunswift eVe details.

\begin{tabular}{|c|c|c|}
\hline Vehicle & Stats & Achievements \\
\hline Sunswift eVe & $\begin{array}{l}\mathrm{L} \times \mathrm{W}: 4.5 \times 1.8 \mathrm{~m} \\
\text { Array: } 4 \mathrm{~m}^{2} \text { at av. } 22 \% \\
\text { efficiency } \\
\text { Battery: } 16 \mathrm{kWh} \\
\text { Top speed achieved: } \\
132 \mathrm{~km} / \mathrm{h} \\
\text { Weight: }<400 \mathrm{~kg}\end{array}$ & $\begin{array}{l}\text { Line honours } \\
\text { (Cruiser Class), } \\
2013 \text { WSC } \\
\text { [ } 3^{1 \mathrm{~d}} \text { overall in class] } \\
\text { FIA Category A } \\
\text { Group VIII Class } 1 \\
\text { International Land } \\
\text { Speed Record - } \\
\text { fastest electric } \\
\text { vehicle over } 500 \mathrm{~km} \\
(107.2 \mathrm{~km} / \mathrm{h})\end{array}$ \\
\hline
\end{tabular}

This was mandated by officials to avoid the car being placed in the "hybrid" category, rather than simply disconnecting the electrics from the PV system. The record itself being broken (Category A Group VIII-1) was set by the GM SunRaycer solar car - a speed identical to the solar- powered-vehicle section of the record list (Cat A Group VII); if GM's car set both the solar and electric records simultaneously, the rules applied to eVe were not consistent and it is clear that the record books for alternative energy vehicles need to be comprehensively cleaned with new, more rigid categories established as more and more attempts are made using solar, batteries, fuel cells, and other novel systems.

\section{A New Professionalism}

The design reviews mentioned in the previous section, which were relatively regular and intensive, were part of a suite of new or newly-formalised initiatives designed by team management to keep the project under control. A lean systems engineering approach was applied by the project manager under mentorship from systems professionals, and the team now operates with a systems engineering team as a defined entity feeding in and out of the other sub-teams such as mechanical, electrical, etc. Project goals, deadlines, the interpretation of rules and regulations, and budget management are all now considerably more transparent and better-documented than in previous years as a result. Additionally, students can better engage with industry by speaking the correct language in communicating ideas and processes.

Although early-adopters of computer-based knowledge management from many years ago, the team now actively and rigorously uses Atlassian's "Confluence" software - a version controlling, bug tracking and wiki-documenting online software. It has allowed the team to collaborate online, document their work as they go, and effectively organise and archive information in the most effective way yet.

The aim of the increased emphasis on knowledge management is to not only bring together everything from engineering design and implementation specifications, thesis reports, budget reports etc., but also to capture the processes, fails and successes along the way - an evolution of prior tools aimed more at repository. The team has reduced the amount of information being lost in emails and by word of mouth - and are now recording, documenting and discussing aspects of building a road legal car in a professional medium. When former students were asked what they felt was the most significant change in the project in recent years, responses included reference to 
these new processes: “...the improved knowledge management and increased external industry support available from Thales", and “... effort into documenting designs and passing on information from generation to generation, there's still work to do here, but I think this has been extremely useful and productive".

Finally, the team has become extremely media savvy, producing effective and creative vision to provide to news agencies as well as engaging more closely with UNSW's media arm to maximize exposure and "control the message". This is congruous with the shifts in internal and external perception of the team assisted by the high-profile achievements, the increased attention to management processes, and the ramping up of outreach activities which involve ever more social media and undertaking the hard work of capturing the attention of digital-native youth.

\section{eVe 2.0}

$\mathrm{eVe}$, at launch, was bare-bones in many respects. It was perceived in the team that TU Eindhoven's winning 2013 WSC Cruiser Class vehicle was awarded higher judging marks for practicality in large part due to their road-legal status in the Netherlands, and thus was crowned the winner despite being considerably slower on the road. However, without the budget to build a new vehicle for 2015, a serious engineering challenge was required to attract, retain and train the new and continuing Sunswift team in what is often seen as an "off" year between WSC campaigns - in the "eVe spirit" of taking the new, interesting path instead of retreading the past, the team has embarked upon a journey to make her a road-legal vehicle for unrestricted travel in Australia.

The largest engineering challenge that the team faces at present is trying to satisfy two different and complex sets of requirements - a new feat in the team's history: a vehicle compliant with both the 2015 World Solar Challenge Cruiser Class Regulations as well as the Australian Design Rules. One set of standards pushes for a "roadworthy" vehicle, while the other pushes for a "race-worthy" vehicle. These types of compliance are quite contradictory - one example would be that the WSC regulations require the installation of a rollbar, while any road-worthy standard in Australia strictly forbids it. This requires extensive work in systems engineering in terms of both understanding and clarifying requirements, as well as dealing professionally with regulating bodies. It is a long-term investment in experience, as it can be anticipated that legal roadworthiness will become the standard rather than the exception at future WSCs.

\section{Education, Impact, and the Next 20 Years}

The breadth of impact of Sunswift is significant, yet in writing this paper the authors became acutely aware of the lack of tangible data to better quantify and analyse this. An immediate recommendation, which likely applies to many other student projects, would be to institute a policy of formal surveying and data-gathering to track participation statistics, student and staff attitudes, alumni employment trajectories and achievements, public outreach, and a metric of skills and knowledge advancements for students directly involved. The latter is of particular significance as many students report that Sunswift was the most rewarding and useful aspect of their degree at UNSW, and in many cases directly determined their career success, yet no academic credit is offered. Additionally, the requirements for involvement (time, knowledge-legacy through reports, development of new initiatives, outstanding service) have historically been vague and usually unstructured, though this is now receiving attention. The following sections discuss some aspects of impact which are able to be addressed presently, as well as some high-level issues which are perceived to be most pressing.

\section{Alumni Success}

Data from a comprehensive survey of alumni and, where possible, their employers will not be available until later in 2015, however we may draw some preliminary observations from those involved with the project over significant lengths of time (i.e. 2 build cycles ( 4 years) or longer) and those who have provided anecdotal feedback when requested.

Project managers and leaders of sub-teams (mechanical, electrical, etc.) appear to be well-trained and well-positioned to leapfrog into managerial or high-responsibility roles - the more recent previous project managers hold or have held positions including: lead aerodynamic development role at a formula one team, CEO of a successful smart-home startup, project manager at Tesla, project manager of major renewable energy infrastructure projects, founder of national environmental impact assessment company, a managerial consultant, and leading solar cell research projects at a large European institute. One former project leader stated, in response to the question "What you felt was the most rewarding/useful aspect of being involved in Sunswift": "Being able to use the car and team as an example of experience that is applicable to a job...most other applicants of comparable age or career progression would not have that." and "the opportunity to manage such a diverse and large group towards a significant/tangible objective [has] been valuable".

Sub-team leaders have gone on to involvement with Americas Cup yacht design, working on Google $\mathrm{X}$ projects, and founding a successful financial network technology firm, amongst many other achievements. These are all extra-ordinary career trajectories, however it is unclear the extent to which Sunswift helped create these opportunities vs. to what extent highly motivated, intelligent, dynamic students would be drawn to those positions and would succeed anyway. Further analysis is required.

When asked what the most rewarding aspect of involvement with Sunswift was, and how Sunswift might help or has helped with their career, all alumni asked responded along similar lines referring to the technical and personal aspects:

"The most rewarding part to me was a combination of the learning, teamwork and the outcomes. It's great to be able to apply things taught at uni and to see how problems can actually be solved and to do this along other talented individuals you can learn from or with. I also think it's pretty amazing looking back the sorts if things that we were able to achieve as students."

"I met many motivated young people, especially engineers, both locally and from teams around the world. This generation of young engineers are now scattered around some of the most interesting tech companies and research centres, which is always a great network to have." 
"Being given responsibility to design part of a real, complex engineering project really early on in my degree was both incredibly overwhelming and exciting all the same time ... I learnt a whole lot of practical design and build skills I would not have otherwise."

"The most useful aspect is the skills gained only in a project context, that can't be done in classes or even industrial training"

“... the networking opportunities that Sunswift provides. I've met half a dozen politicians, dozens of business owners, made strong relationships with several dozen academics."

This anecdotal evidence also speaks to the great value of the project to prospective employers, who are able to tap a potential market of engineers already experienced with relatively large budgets, extremely tight timelines, design, manufacturing and testing of actual products, and perhaps the most intangible but useful: many of the students have experienced real-world failure in their engineering endeavours, but without the more significant consequences which that might entail in industry.

Yet if the value of the project to industry and employers is high, this is rarely expressed explicitly to university management. Closer industry links, particularly through champions and mentors, is required such that a "critical mass" of corporate voice can make its opinion heard on supporting and structuring the project in the coming years.

\section{Outreach - Public and Schools}

Sunswift has a long history of involvement in outreach (figure 9): the Faculty and UNSW promote their engineering programs, and the specific highlights of the vehicle achievements bring prestige and media attention to focus on the institution (the combined value of media exposure from eVe's WSC and land speed record success has been estimated to exceed $\$ 2 \mathrm{~m}$ ). The new ability to take a vehicle to schools and public places and have people sit in it, have their photo taken, and imagine themselves driving it in day-to-day-life, has been a bonus to the team in significantly raising their public profile.

Having sponsors and politicians (from all major parties) visit and drive eVe at track days has assisted in greatly expanding the potential network of influential supporters - almost 100 people have driven the car now: no special training is required. Trade show appearances are now common, and sponsors request the car at their stand as a draw-card.

Sunswift presented directly to over 1000 school students in 2014 alone, and hundreds more have interacted with the car at events. School visits typically feature 2 presentations: one where students sit at the car and listen to how eVe was built, what she's made out of and features of her design, who Sunswift are, the WSC and world record attempts. The other involves classroom powerpoint presentations on topics such as "why do we need solar cars?", "how do solar panels work?", etc. tailored to whichever yeargroup is involved. The team has also run "build a solar car" workshops leading to playground races, following the successful motivational active learning model for high school students described by Wellington [4].
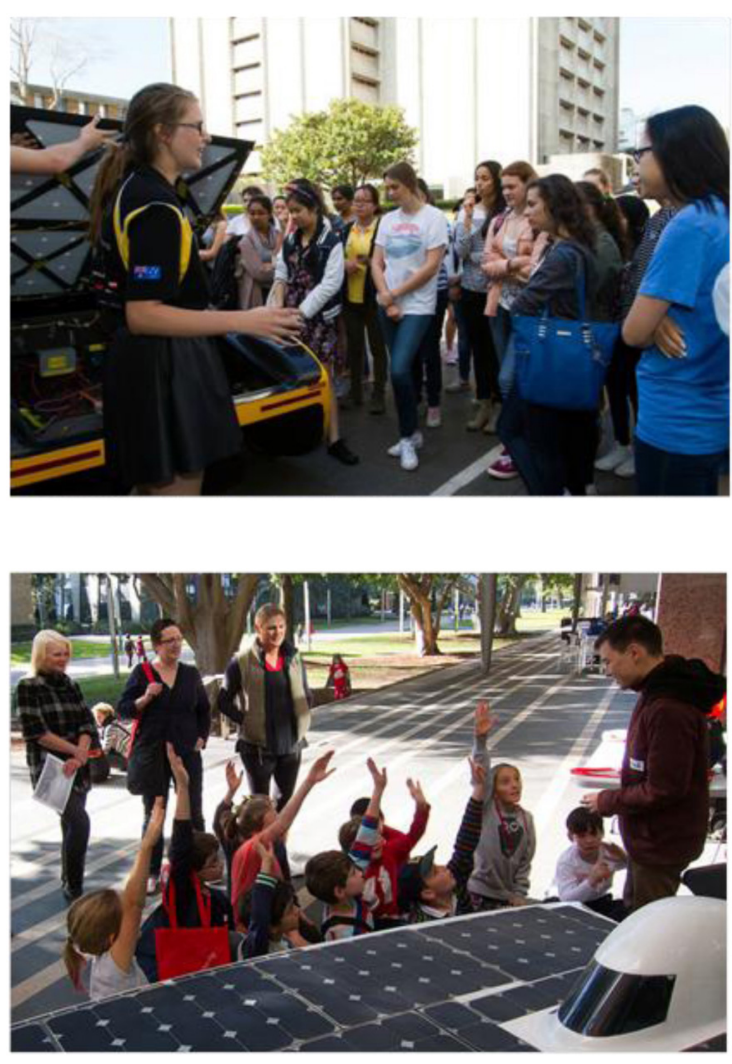

Figure 9. High school students visit UNSW for a Women in Engineering event (top), and (below) primary school children learning about Ivy during a Faculty outreach event.

\section{Female and International Student Participation}

UNSW's Faculty of Engineering has a stated target of achieving $25 \%$ female enrolments by 2020; the number currently sits at less than $20 \%$, though this is skewed heavily towards biomedical (30\%) and chemical engineering $(40 \%)$ - mechanical and manufacturing engineering is at $14 \%$, at the low end along with mining, computer science, petroleum and electrical engineering (all $<20 \%$ ). First year female enrolments are edging up to $22 \%$ as of $2014^{1}$, with the faculty pursuing a number of programs to encourage girls to consider a career in engineering. This contrasts with - and is a response to - the statistics of Australia's professional and accrediting body Engineers Australia []ㅡ, where women constitute $11 \%$ of the total membership (and only $7.5 \%$ of the engineering team membership). Australia-wide, young women account for approximately $14 \%$ of acceptances in engineering courses at university. This figure itself stems from historically low female enrolment levels in high school physics, with the numbers only slightly better for other science subjects [ $[5]$.

According to Dr. Alex Bannigan, UNSW's Women in Engineering coordinator, "exposing girls to the idea that engineering is a social, creative, helpful career can make a really big difference to their perceptions" . Sunswift is a unique project in that it is positioned at the environmentally-conscious end of the scale and has demonstrable outreach in the public sphere where events are specifically designed to promote renewable technologies, sustainable transport, high school student and particularly female student interest in engineering, and it represents something that is more appreciably different and continually-evolving than the FSAE project. Lehr writes ““"... efforts

1. http://www.smh.com.au/national/tertiary-education/time-to-engineer-change20140804-3d4al.html 
to recruit women to engineering may be aided by expanding recruitment messages to include an emphasis on 'making a difference, helping, or serving as a role model for others as a woman and/or minority in the field" "[]]. The fact that it is clearly positioned as a Faculty project, rather than FSAE which comes more strictly under the domain of Mechanical and Manufacturing Engineering, also facilitates the draw of students from a wider background.

For the years in which data was available (Sunswift 1995, 1999, 2001, 2007 to 2015 inclusive; FSAE 2007, 2009 to 2014 inclusive) Sunswift has averaged around 4 girls on the team, which represents around $25 \%$ participation. FSAE's average has been just under 2, representing close to $10 \%$. The numbers correlate closely with the Faculty and the School of Mechanical and Manufacturing Engineering female enrolments respectively. These numbers are approximate as the actual "size" of the team is difficult to quantify where possible the actual event teams of between 10 and 25 students for Sunswift and approximately 15 for F-SAE rather than the wider team has been evaluated (the wider team may have two to three times as many students for Sunswift and approximately an additional $30 \%$ for FSAE - with similar percentages of female participation).

All of this might suggest a stronger role could be played by Sunswift in integrating into coordinated efforts to bolster female engineering participation more broadly, particularly given the high profile it has enjoyed and with 3 female project leaders from the most recent 6 . The schools of Electrical, and Mechanical and Manufacturing Engineering in particular are where most of Sunswift's cohort originate, and they are also amongst the lowestranked for female enrolment.

Table 6. Participation rates

\begin{tabular}{|l|l|l|l|l|}
\hline & $\begin{array}{l}\text { UNSW } \\
\text { Faculty of } \\
\text { Engineering }\end{array}$ & Sunswift & $\begin{array}{l}\text { UNSW } \\
\text { F-SAE }\end{array}$ & $\begin{array}{l}\text { Australian } \\
\text { Engineering } \\
\text { Workforce }\end{array}$ \\
\hline$\%$ female & $19 \%$ & $25 \%$ & $10 \%$ & $11 \%$ \\
\hline $\begin{array}{l}\% \\
\text { international }\end{array}$ & $37 \%$ & $10 \%$ & $\mathrm{n} / \mathrm{a}$ & $\mathrm{n} / \mathrm{a}$ \\
\hline
\end{tabular}

Mills indicated "This is where the greatest challenge still remains: to change the culture and sometimes hidden power constructs of engineering education and workplaces so that engineering becomes a profession that provides realistic opportunities for all of its members to enjoy successful, rewarding and long-term careers. [7]]" - on the surface at least, Sunswift appears to be achieving this change, and can be a tool in making it scalable and sustainable.

Another statistic is that compared to UNSW's exceptionally high $37 \%$ level of undergraduate enrolment for overseas students (including those speaking English as a second language), the current team comprises less than $10 \%$ for these categories. Averages for previous years fall between 10 and $15 \%$. A fruitful avenue for further investigation would be to determine what aspects are influential here - are language barriers significant? Cultural ones? Is it a matter of the expense of the degree vs. a project which doesn't offer any academic credit? Are there other factors at play? Interviewing those who do and do not participate would elucidate on this and help direct efforts to further adjust the makeup of the team to be even more representative of the engineering student body at the institution.

We have not focused on the percentages for participation from local students with "minority" ethnic backgrounds, as statistics are not as readily available for before 2009 - however, Sydney and UNSW's diverse student population helped ensure that non-anglo-saxon/ non-white background students comprised approximately $50 \%$ of the Sunswift cohort over the last half-decade. This statistic alone is the major reason previous statistics were not as readily available as for female or foreign language speakers, as such team members were not remembered as being especially distinct, or in other words not "minority" at all - subjectively, a pleasing reason for a lack of data.

\section{Opportunity Cost of Involvement}

The ability of students to justify involvement with Susnwift for zero academic credit - at the potential expense of grades or having to repeat subjects or extend their degrees - is likely to decrease, particularly if current proposals for deregulating fees lead to higher costs and debts for students. Involvement with Sunswift comes with risk to academic performance.

Late final year theses, missed assignments, failed exams and repeated subjects are a well-known feature of the team for several students per year. This is explicitly acknowledged - involvement is likely to impact weighted average grades - though actual failure at any subject is strongly discouraged by team management as it can be an expensive, involvement-threatening, blow.

Former team members, including project managers, interviewed for this paper were asked "How did your grades, assignments, WAM (weighted average mark, /100), and general academic performance suffer due to your involvement with the team?". The responses were mostly negative: "Academically, the cost for me was failing 4 subjects and eliminating my chances of getting the award of honours.", "My WAM dropped an average of 10 marks. Sunswift definitely had a noticeable, but bearable impact on my grades", and "I do think on average my term averages have seen a hit of up to 10 points depending on how busy things were with Sunswift but this is a very small price to pay to pay for the experience.".

That mention of a positive upside was common, however. For instance: "[my grades] suffered significantly due to my involvement particularly at the start of my degree, but towards the end it may have even helped? ... while I wasn't going to classes, the experience that I got through my involvement probably helped me approach subjects such as design and thesis better equipped than most other students. The subjects that could not directly draw from the project ... suffered.", and "grades in general dropped a bit because there were a lot of skipped lectures, and assignments done in a mad rush... but my marks for any hands on or design subjects were always high, and that's mostly thanks to Sunswift!". One respondent did note "Sunswift has didn't really affect my WAM at all. If anything, it helps you get organized, plan your time and meet deadlines".

It's clear that students have great dedication and even affection for the project and most are willing to sacrifice marks for the experience, and note that it helps them become much better at design and creative 
engineering aspects of subjects (figure 10). Better integration of the project into class work such as design subjects and mechanical/PV core subjects for use as examples may improve this further. A roadmap for this has already been laid out by Carroll and Hirtz []], who established a multi-disciplinary design course based around University of Missouri-Rolla's solar car team circa. 2001; they described a full course which introduces general topics but with the constant example of how to design and build a solar-powered racing car, which also serves to get new solar car team members "up-tospeed" in how to design such a vehicle in a formal academic setting. They conclude in a report on the remarkable success of this approach: "they [students] developed a sound management structure and approached this project in a more professional manner than do most corporations. The pay-off was winning the 1999 Sunrayce competition." - similar observations about making a solar car a formal senior capstone design course at the US Military Academy have also been made [9]. This is a model that UNSW can investigate.

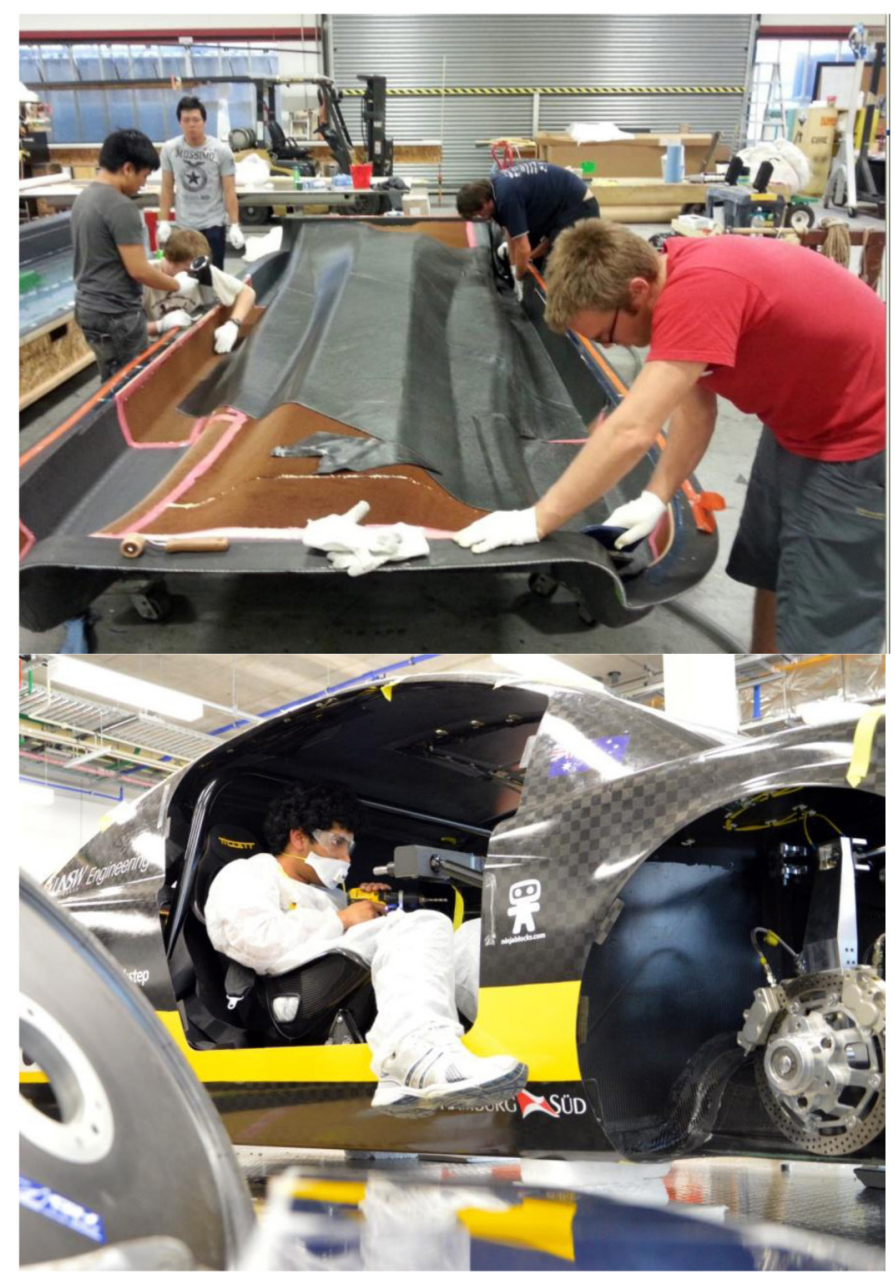

Figure 10. Experience not available in the classroom: the composites team travelled to New Zealand in 2013 to fabricate the moulds and car shells for eVe with industry partner Core Builders Composites (top), then completed the manufacture and assembly of the entire vehicle at UNSW in approximately 4 months (bottom).

No student interviewed for this paper expressed any regret about being on Sunswift, and the value to their careers and to their employers was considerable. One student responded "Having met many teams from around the world, it was clear that teams really benefitted from having the solar car project somehow officially credited as part of their studies: something which we haven't achieved yet at UNSW."

It should not be acceptable that a student can fail subjects or drop $10 \%$ (and at least an honours grade) from their average degree mark as a consequence of undertaking work that is often more complex, thorough and time-consuming than a 12 unit of credit honours thesis, or from completing the design, test and manufacture of a part that is more challenging and real-world than those in design subjects. A framework to create a subject that has well-defined, assessable deliverables will not be difficult to create and is very likely to assist with the retention and focus of team members, as well as potentially increasing the quality of work on the car by bright students chasing high marks. Other universities in Australia have pursued this strategy to good effect for Formula SAE [10, 2], there is no reason it cannot or should not be done with a successful solar car racing team.

E-portfolios, peer-reviewed pitches of designs, and feedback-enriched final technical reports would be valuable to the team, and are readily assessable. This would bridge the credit problem for the $90 \%$ or so students in the team who are not in a position to do a car-related final year thesis project.

\section{Beyond WSC 2015}

Does the project have the longevity of another 20 years? The challenge for the team post-2015 WSC will be to maintain the momentum by establishing another set of exciting, motivating goals to work towards over the following 4 years with a new vehicle and long shadows cast by recent achievements. Logical goals could be to build a more capable, comfortable, refined car and perhaps compete in races overseas, yet such goals imply that as much as a $\$ 1 \mathrm{~m}$ budget (including in-kind) may be required, over double that devoted to eVe. This could be achieved with a concerted effort to strategically build upon the good work done in recent years in developing sponsor relations; ongoing and value-creating relationships are critical for the success of such an approach. Putting more effort in to learning from the most successful teams in this area would help. But are such goals good value for the primary backer, UNSW Australia, and are they in keeping with the spirit of innovation and thought-leadership that has marked the most ambitious of the team's endeavours? How would the team "sell" the significance?

Within the next decade it is likely that the sight of electric vehicles crossing a continent or racing in the street will cease to be a novelty, regardless of the power source, given the progress made by commercial manufacturers such as Tesla in facilitating long-distance all-electric motoring. A former Sunswift project leader from the early years commented "We were frequently asked by the public 'when will these cars be available to drive?', I suspect that question has already been answered by [mass production] electric cars". It is undeniable that solar-harvested power delivered to batteries at discrete charging stations is more practical than having expensive solar panels on the vehicle, even if that expense has reduced by as much as $90 \%$ (for panel efficiencies in the teens) since Sunswift was founded ${ }^{2}$. Being at the efficiency forefront continues to be an exceptionally high-cost proposition for all solar teams 
While the energy efficiency of the cars will remain impressive and continue to improve with cell enhancements, and while the engineering challenge to students will remain great, it is unlikely to engage with the public again once they are used to the "new" type of solar car ("practical" 2 or 4-seaters). The WSC organizers will have to continue to innovate considerably to retain the level of public interest that it will take into the 2015 race with an expanding field of Cruiser Class solar cars. However, with a million-plus dollar budget team winning each event since the early 2000's and several before that, the competition stands in stark contrast to F-SAE type competitions. There, budgets are lower (perhaps by an order of magnitude) and teams can achieve marked improvements year to year without necessarily doubling or quadrupling their budgets or sponsor involvement. If the university backers feel they are no longer getting "prestige" value from a project that appears to be - compared to FSAE-Electric for example - expensive and risky, then there is always concern that they will seek to scale back or cancel the project regardless of the excellent training and experience which it will continue to provide to students. Universities increasingly need to find greater "bang for their buck", but they also need to distinguish and differentiate themselves in what is now the most competitive international market for the student dollar - Sunswift will have to position itself clearly as an enabler of both these aspects.

For the Sunswift project, which has a proud history of innovation, the focus in this new shift to road legal cars is an interesting twist in that the majority of energy is now devoted into incorporating existing technology into solar cars, rather than developing new innovations that lead industry. This is unlikely to be sustainable in producing technological advancements in the way that motor controller development and battery management breakthroughs have been in the past. The EV industry has in some ways accelerated ahead of one of its greatest champions - the key may be to institute a significantly closer relationship between industry and solar car projects so that the more in-depth work (the kind that makes up masters and undergraduate research projects) is of benefit to all. The project's viability and sustainability may therefore rest on increasing support and involvement from industry, as well as a continued broadening of the mission of the team far beyond the World Solar Challenge.

Graduates have historically not entered the automotive industry other than one or two overseas in the motorsport arena. Students attracted to the solar car team are from a broader, more representative base than those on UNSW's FSAE Team, yet are far less likely to be passionate about cars and motorsport. Drawing clearer links between the project and new initiatives such as the Formula-E series and other electric categories, as well as the increasing prevalence of electric cars in everyday life, may change this.

Long-term on outreach, the team could work more closely with schools and teachers. Instead of a quick visit, Sunswift could help to provide integrated curriculum content that links the car with concepts in science and other technical subjects, making the eventual visit more meaningful for students and the overall approach better for re-enforcing deeper learning.

Pushing the perceived boundaries will be critical in the next chapters of Sunswift. Becoming road legal (figure 11) is hopefully just the next step of many. Whether others will be a greater focus on autonomous systems, or a push towards genuine economic viability for a solar-electric hybrid, or a leap into genuinely unexpected territory, the "new thing" is what the team should always strive to attempt for the most challenging and rewarding educational experience.

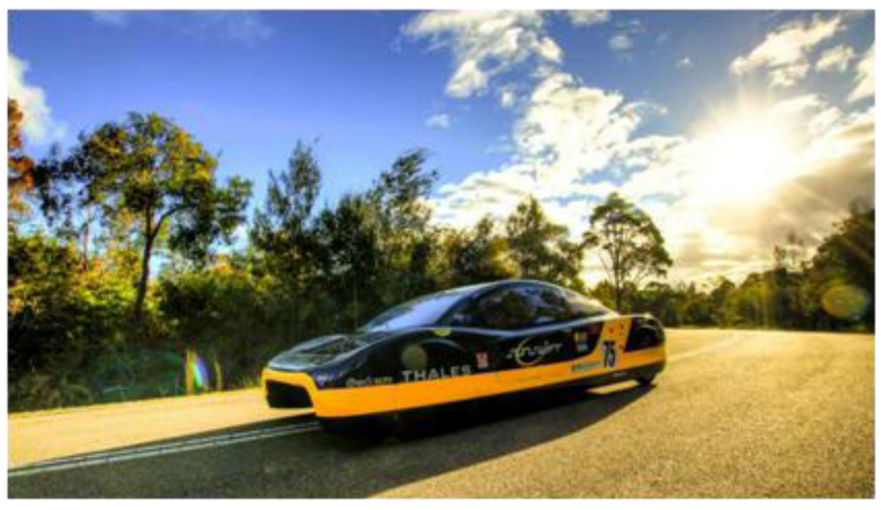

Figure 11. eVe is in the process of being redesigned to become Australia's first unrestricted road-registered solar/electric car. (photo credit: Daniel Chen)

\section{Conclusions}

In its 20 years, the Sunswift project has proven to be of enormous value to the core students who have been involved, their eventual employers, and UNSW's Faculty of Engineering. It has also been used to inspire younger students to pursue degrees and careers in science and engineering, and more recently this inspirational position has extended to the general public with a series of high-profile record attempts demonstrating the promise and potential of alternative energy vehicles.

It is clear that aspects of the project need to be quantified more effectively in order to better assess the educational impact, and therefore to improve the structure and sustainability of the project. In many ways it is only just hitting its stride. It is the opinion of the authors that the project involves a time commitment, learning outcomes, and unique hands-on experience that should place it at the core of the curriculum rather than "club" status which garners no academic credit and can infact reduce grade point averages. Alumni report near-universal satisfaction that Sunswift was the most valuable aspect of their degree, and that value should translate to the transcript.

The future of Sunswift is by no means assured, however in terms of achievement, public profile, team depth, and professionalism, Sunswift may never have been stronger. The challenge now will be to plan effectively for the medium term in order to keep the team at the forefront of what is new, and most relevant to industry, in order to provide the most useful, educationally-rewarding, high-profile training experience for UNSW Australia's engineers in the age of the electric car.

\section{Contact Information}

2011-2014 Academic Adviser Dr Graham Doig: gcdoig@calpoly.edu.

2014-2015 Project Manager Hayden Smith: hayden.smith@sunswift.unsw.edu.au 


\section{Acknowledgments}

The authors acknowledge the contributions to the project made by the many team members involved past and present, UNSW's Faculty of Engineering and the various sponsors and donors who keep Sunswift operational. Many thanks to Alex Bannigan and Stuart Upton from UNSW's Faculty of Engineering for providing detailed statistics on enrolment, and to 2014/15 Sunswift Business Team Leader Rob Ireland for providing information on media coverage and outreach activities. Any subjective views expressed in this paper by the authors are their collective own and do not represent the institutional views and positions of UNSW Australia, its Faculty of Engineering, or Sunswift Solar Racing Team.

\section{References}

1. Savage, R. N., Chen, K.C., and Vanasupa L. "Integrating project-based learning throughout the undergraduate engineering curriculum.” Materials Engineering (2007): 1-18.

2. Vishy, Karri, Bullen Frank, and Rossmanek Peter. "Design and construction of formula SAE race car as project based learning." In Towards Excellence in Engineering Education: Proceedings of the 12th Australasian Conference on Engineering Education, 7th Australasian Women in Engineering Forum, p. 427.

Queensland University of Technology, 2001.

3. Doig G., Beves, C, Aerodynamic Design and Development of the Sunswift IV Solar Racing Car. International Journal of Vehicle Engineering, Vol. 66, No. 2.

4. Wellington, R. P. "Model solar vehicles provide motivation for school students." Solar Energy 58, no. 1 (1996): 137-146.
5. Kaspura A. "Women in Engineering: A Statistical Update", Engineers Australia,1-27, 2012

6. Lehr, J. L., Finger H., and Kwang B. "When, Why, How, WhoLessons from First Year Female Engineering Students at Cal Poly for Efforts to Increase Recruitment," Proc. Annual Conf. of the Pacific Southwest Section of the American Soc. for Eng. Education, San Luis Obispo. 1-26, 2012.A

7. Mills, Julie E. "Reflections on the past, present and future of women in engineering." Australasian Journal of Engineering Education 17, no. 3 (2011): 139.

8. Carroll, Douglas R., and Hirtz Paul D.. "Teaching MultiDisciplinary Design: Solar Car Design.” Journal of Engineering Education 91, no. 2 (2002): 245-248.

9. Catalano, George D., and Tonso Karen L.. "The Sunrayce'95 Idea: Adding Hands-on Design to an Engineering Curriculum." Journal of Engineering Education 85, no. 3 (1996): 193-199.

10. Watkins S., and Pearson G.. "Motivating students to give world class performance via FSAE.” In 20th Annual Conference for the Australasian Association for Engineering Education, 6-9 December 2009: Engineering the Curriculum, p. 1021. Engineers Australia, 2009.

\section{Definitions/Abbreviations}

CAN - Controller area network

CFD - Computational Fluid Dynamics

FIA - Federation Internationale d'Automobile

UNSW - University of New South Wales (now UNSW Australia)

WSC - World Solar Challenge

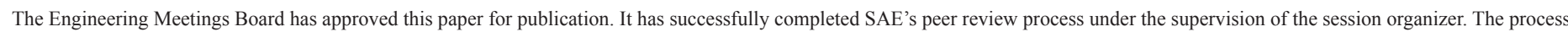
requires a minimum of three (3) reviews by industry experts.

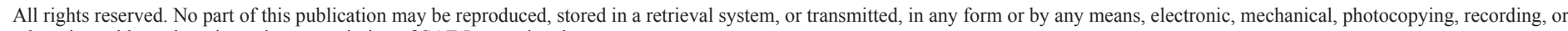
otherwise, without the prior written permission of SAE International.

Positions and opinions advanced in this paper are those of the author(s) and not necessarily those of SAE International. The author is solely responsible for the content of the paper.

ISSN 0148-7191

http://papers.sae.org/2015-01-0073 